Case Series

\title{
Case series on external auditory canal cholesteatoma: an entity often misdiagnosed
}

\author{
Priti S. Hajare, O. Padmavathy*
} Department of Otorhinolaryngology, Head and Neck Surgery, Jawaharlal Nehru Medical College, Belgaum,
Karnataka, India

Received: 29 March 2020

Revised: 29 April 2020

Accepted: 30 April 2020

\author{
*Correspondence: \\ Dr. O. Padmavathy, \\ E-mail: paduop@gmail.com
}

Copyright: (C) the author(s), publisher and licensee Medip Academy. This is an open-access article distributed under the terms of the Creative Commons Attribution Non-Commercial License, which permits unrestricted non-commercial use, distribution, and reproduction in any medium, provided the original work is properly cited.

\begin{abstract}
External auditory canal (EAC) cholesteatoma is a rare disease. EAC cholesteatoma presents with chronic dull aching pain with normal hearing. It is diagnosed by clinical examination and radiological investigation. Due to its rarity it is important to differentiate it from other external ear conditions. We prospectively analysed four cases of cholesteatoma of the external auditory canal in a period of 18 months. All of our patients underwent surgery. In three cases, the cholesteatoma was restricted to the external auditory canal, while in one case it was extending into the antrum. A proper clinical examination with radiological investigations will be helpful in the diagnosis and for proper management of the disease.
\end{abstract}

Keywords: Cholesteatoma, External auditory canal cholesteatoma, High-resolution computed tomography

\section{INTRODUCTION}

Primary auditory canal cholesteatoma is an invasion of squamous epithelium into a localized area of bony erosion with or without bony necrosis. External auditory canal (EAC) cholesteatoma is a rare condition. Compared to that of middle ear cholesteatoma which is 9.2 per year per 100,000, the incidence of primary EAC cholesteatoma is 0.3 per 100,000 population. ${ }^{1,2}$ Toynbee, in 1854, was the first to describe cholesteatoma as epidermal sheets originating from external auditory canal. The clinical presentation of EAC cholesteatoma include long standing otorrhoea with dull aching chronic pain with normal hearing. ${ }^{3}$ The etiology and pathogenesis of the disease is unclear but it is considered to be due trauma to external auditory canal, stenosis of ear canal, long standing inflammation of the canal or spontaneous. Although EAC cholesteatoma is a benign condition it has the potential to spread and destruct surrounding structure.
The process of bone destruction is unclear but various theories that has been proposed include increased pressure caused by enlarging cholesteatoma (pressure theory), by the release of proteolytic enzymes like acid phosphatase, collagenase (enzymatic theory), pyogenic osteitis. External auditory canal cholesteatoma has been staged based on histological clinical and radiological findings which helps in deciding the surgical management. Differential diagnosis of EAC cholesteatoma include keratosis obturans, benign necrotising otitis externa, EAC carcinoma. ${ }^{4}$

A proper diagnosis is required to differentiate these conditions and for further management. Computed tomography scan plays an important role in diagnosis and differentiating it from other conditions of external auditory canal. So, the aims of this paper is to present a series of 4 cases of EAC cholesteatoma and the modes of presentation with staging and treatment modalities. 


\section{CASE SERIES}

\section{Case 1}

A 19-year old male presented with complaints of left ear discharge since 5 months and decreased hearing. On otoscopic examination a pinkish fleshy mass was noted in the external auditory canal covering the entire EAC which was firm in consistency and did not bleed on touch (Figure 1). Tympanic membrane was not visualised. Pure tone audiometry showed mild conductive hearing loss of $20 \mathrm{~dB}$. High-resolution computed tomography (HRCT) temporal bone revealed soft tissue density lesion involving external auditory canal with significant erosion of anterior and inferior walls of the EAC (Figure 2). Surgical intervention was planned and intraoperatively fleshy polyp with cholesteatoma flakes were present associated with anterior defect over temporomandibular joint and inferior wall of EAC. Middle ear and ossicles were intact. Disease clearance was done by canaloplasty. Anterior wall reconstruction with conchal cartilage was done and EAC was lined with temporalis fascia. Meatoplasty done. Tissue was sent for histopathological examination and confirmed EAC cholesteatoma. Patient was followed up for three months and was completely disease free.

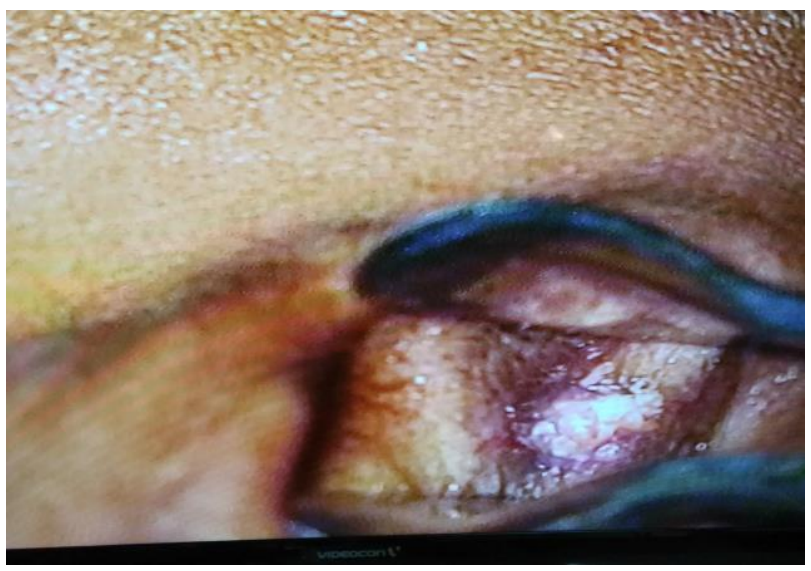

Figure 1: Pink fleshy mass occupying entire EAC.

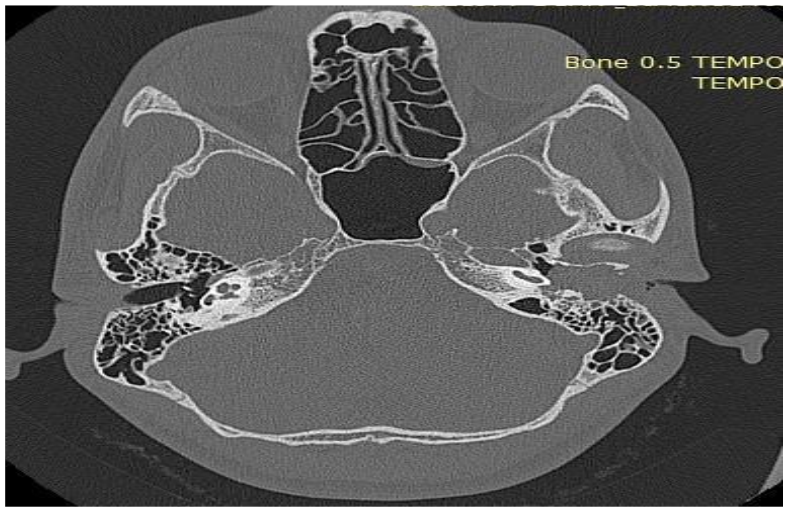

Figure 2: HRCT showing soft tissue density lesion in EAC with significant erosion of anterior and inferior walls of the EAC.

\section{Case 2}

A 63-year-old female presented to us with complaints of left ear pain and intermittent left ear discharge since 1 year. Otoscopic examination revealed normal and intact tympanic membrane with scanty amount of discharge in left external auditory canal. After suctioning erosion of posteroinferior canal wall was noted. HRCT revealed defect in EAC and involving air cells in mastoid (Figure $3)$. Pure tone audiometry showed moderate conductive hearing loss of $40 \mathrm{~dB}$ in left ear and right ear was normal. Patient was taken up for exploration. Intraoperatively defect in posterior wall of external auditory canal was noted. Cholesteatoma sac was seen involving posterior and inferior canal wall extending into mastoid antrum. Tympanic membrane was intact and middle ear was free and ossicles were intact. Canal wall was lowered in view of complete clearance of the disease and meatoplasty was done. The tissue was sent for histopathology which confirmed the diagnosis of cholesteatoma. Patient was followed up for 6 months and had a proper healed cavity with no recurrence.

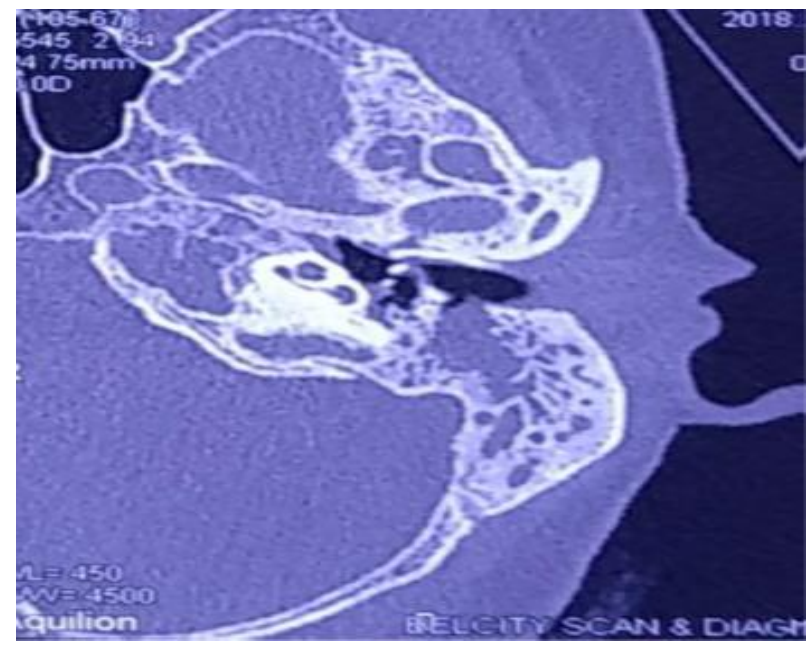

Figure 3: HRCT showing soft tissue lesion in EAC with defect in inferior wall of EAC.

\section{Case 3}

A 22-year-old male presented to OPD with left sided dull aching ear pain since one month associated with left ear discharge since 10 days. History of trauma to the left ear 6 months back was present. Otoscopic examination revealed a pink fleshy mass occupying the whole meatus with narrowing of meatus. It was tender, firm in consistency did not bleed on touch (Figure 4). Tympanic membrane could not be visualised. Audiometry of left ear showed mild conductive hearing loss of $26 \mathrm{~dB}$. HRCT revealed soft tissue density lesion filling the external auditory canal with defect in the posterior and inferior wall of external auditory canal. Surgery was planned and the mass was noted arising from the posterior EAC was noted. After clearing the mass cholesteatoma sac with flakes eroding the posterior canal wall was noted. 
Tympanic membrane was intact. Disease clearance done by canaloplasty and defect covered with temporalis fascia. Patient was followed up for 6 months and there was no recurrence.

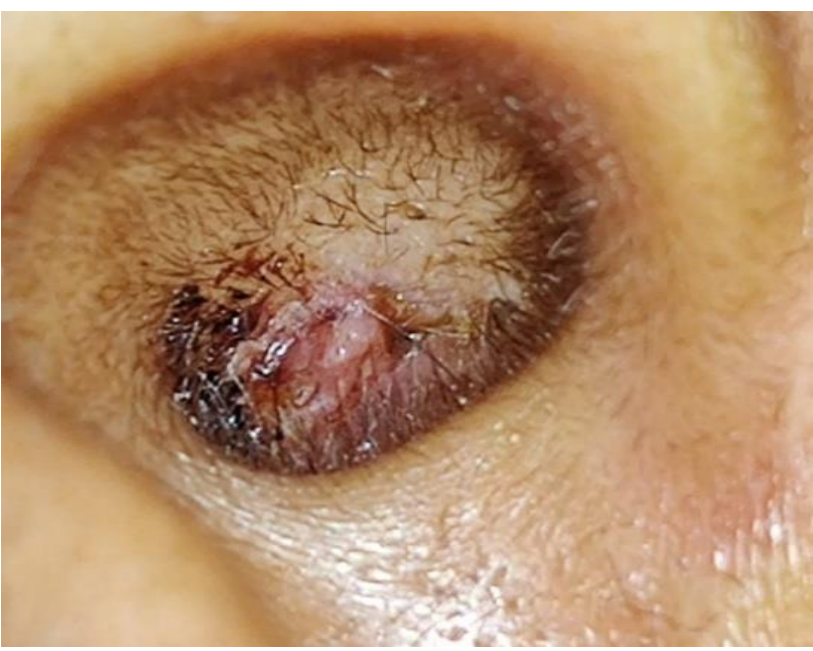

Figure 4: A pink fleshy mass occupying the whole meatus.

\section{Case 4}

A 13-year-old female presented to OPD with severe right ear pain with history of impacted wax and repeated cleaning attempts outside associated with purulent discharge on and off with normal hearing. On otoscopic examination meatus was narrowed with granulation tissue and debris were seen. Tragal tenderness was present. Child gave history of vasovagal attack during attempts of cleaning. Suspecting keratosis obturance, patient was taken up for emergency clearance under general anesthesia. Intraoperatively, after removing the debris, EAC was filled with cholesteatoma sac extending anteriorly to temperomandibular joint, inferiorly eroding canal wall and posteriorly extending into mastoid cortex. Tympanic membrane was intact. Disease was cleared completely by canaloplasty and the defect was covered with tragal cartilage. EAC defect was covered with temporalis fascia and wide meatoplasty was done.

\section{DISCUSSION}

Cholesteatoma is a three dimensional sac like structure lined by keratinized squamous epithelium. Most common type of cholesteatoma is middle ear cholesteatoma which can be congenital or acquired. External auditory canal cholesteatoma is a rare condition with incidence of 1.2 per 1000 new otological cases..$^{1,2}$

The exact etiology of EAC cholesteatoma is unclear. Most cases are spontaneous or occur after surgery and or due to trauma in the auditory canal, although ear canal stenosis or obstruction has also been described as a causative factor in literature. In our study two cases were spontaneous and other two was following trauma associated with narrowed EAC which is consistent with the literature. The clinical presentation of EAC cholesteatoma include otorrhoea with dull aching chronic pain and normal hearing. These findings were consistent with our experience where all four patients had dull aching ear pain and ear discharge. A study by Vrabec and Chaljub in 12 patients with spontaneous EAC reported no hearing loss. But in our study two patient had mild conductive hearing loss, one patient had moderate conductive hearing loss and one patient with normal hearing. External auditory canal cholesteatoma must be differentiated from a similar external ear condition, the keratosis obturans.

Keratosis obturans is the accumulation of a large plug of desquamated keratin in the external auditory meatus, clinically presenting with acute severe otalgia and a conductive hearing impairment with gross widening or ballooning of the ear canal whereas in primary auditory canal cholesteatoma there is invasion of squamous epithelium into a localized area of bony erosion with or without bony necrosis, clinically with a dull aching pain with normal hearing with cholesteatoma flakes and debris. $^{3}$

Nairn et al on basis of histology staged EAC cholesteatoma as stage I epithelial hyperplasia, stage IIa/b periostitis hyperplasia with erythema, or denuded but not eroded bone, stage III canal wall erosion and bony sequestrum and stage IV Invasion into adjacent structures. $^{5}$

Shin et al on basis of clinical and radiological finding staged EAC cholesteatoma as stage I limited to the external auditory canal, stage II invades the tympanic membrane as well as ear canal, stage III creates a defect of the EAC and involves the cortex of mastoid bone and stage IV involves areas beyond the temporal bone. ${ }^{6}$

This classification also includes treatment suggestions like stage I with local care or canaloplasty, stage II with canaloplasty with tympanoplasty, stage III with the above and mastoidectomy and canal wall reconstruction and stage IV with removal of cholesteatoma using various techniques.

In all our four cases it was observed that the cholesteatoma sac from the external auditory canal contained with it the necrotic bone fragments with cholesteatoma flakes consistent with typical findings of an external auditory canal cholesteatoma. In addition there was bony defect noted in the external auditory canal. Two cases had defect in the posterioinferior canal wall and two cases had defect in inferior canal wall consistent with the study of Ho et al on 28 patients, where the most frequent locations of EAC cholesteatoma with bony invasion were the posteroinferior $(40 \%)$, inferior $(30 \%)$, posterior $(20 \%)$, and posterior-inferior-anterior $(10 \%) .^{7}$ All cases had intact tympanic membrane and middle ear was not entered. We have staged the EAC in our study as described in (Table 1). 
Table 1: Staging observed in the study cases.

\begin{tabular}{|lllll|}
\hline Cases & Intraoperative finding & Radiological finding & Surgical management & Staging \\
\hline $\mathbf{1}$ & Limited to EAC & Defect in inferior wall of EAC & Canaloplasty & I \\
\hline $\mathbf{2}$ & $\begin{array}{l}\text { Disease extending to } \\
\text { mastoid }\end{array}$ & $\begin{array}{l}\text { Defect in posterior and inferior wall } \\
\text { of EAC }\end{array}$ & $\begin{array}{l}\text { Canaloplasty with } \\
\text { mastoidectomy }\end{array}$ & III \\
\hline $\mathbf{3}$ & Limited to EAC & $\begin{array}{l}\text { Defect in posterior and inferior wall } \\
\text { of EAC }\end{array}$ & I \\
\hline $\mathbf{4}$ & $\begin{array}{l}\text { Canaloplasty } \\
\text { antrum }\end{array}$ & $\begin{array}{l}\text { Defect in the inferior wall and } \\
\text { extension into mastoid cortex }\end{array}$ & $\begin{array}{l}\text { Canaloplasty, } \\
\text { tympanoplasty and canal } \\
\text { wall reconstruction }\end{array}$ & III \\
\hline
\end{tabular}

The goal of surgery is complete excision of cholesteatoma and necrosed bone to get a smooth canal wall to prevent further disease progression. The type of surgery required depends on disease extension. Surgical interventions include canaloplasty with exteriorization if disease is localised to the canal only. If the middle ear or mastoid cavity is involved, then modified radical mastoidectomy is done to clear the disease. To cover the bony defect after removing cholesteatoma, various tissues used are soft tissue flap, conchal cartilage, and temporalis fascia. The destructed bone must be removed, and raw area covered with temporalis fascia or a split-skin graft. In all our cases the bony defect was covered with conchal or tragal cartilage and covered with temporalis fascia. All our cases were sent for histopathological examination and confirmed as cholesteatoma. The complications of EAC cholesteatoma include facial palsy, mastoid cavity invasion, ossicular erosion, labyrinthine fistula, if the condition is not timely diagnosed and treated. The intracranial complication from primary EAC is extremely rare. ${ }^{7-10}$ There was no complication noted in our study.

\section{CONCLUSION}

External auditory canal cholesteatoma is a rare condition. Due to its close similarity with the other conditions of EAC, it is important to know in detail about the EAC cholesteatoma for proper diagnosis and treatment.

Funding: No funding sources

Conflict of interest: None declared

Ethical approval: Not required

\section{REFERENCES}

1. Verma H, Dass A, Singhal SK, Gupta N.Outer auditory canal cholesteatoma. Int $\mathbf{J}$ Health Allied Sci. 2017;6:230-2.

2. Aswani Y, Varma R, Achuthan G. Spontaneous external auditory canal cholesteatoma in a young male: imaging findings and differential diagnoses. Indian J Radiol Imaging. 2016;26:237-40.

3. Lesser THJ. Keratosis obturans, primary auditory canal cholesteatoma and benign necrotizing otitis externa. In: Scott-Brown's Otorhinolaryngology Head and Neck Surgery. 8th ed. CRC Press; 2018: 941-946.

4. Dhingra P, Pusalkar AG. Spontaneous External Auditory Canal Cholesteatoma: Case Series and Review of Literature. Indian J Otolaryngol Head Neck Surg. 2020;72:86-91.

5. Naim R, Linthicum F Jr, Shen T, Bran G, Hormann K. Classification of the external auditory canal cholesteatoma. Laryngoscope. 2005;115(3):455-60.

6. Shin SH, Shim JH, Lee HK. Classification of external auditory canal cholesteatoma by computed tomography. Clin Exp Otorhinolaryngol. 2010;3(1):24-6.

7. Ho KY, Huang TY, Tsai SM, Wang HM, Chien CY, Chang NC. Surgical treatment of external auditory canal cholesteatoma. J Int Adv Otol. 2017;13(1):913.

8. Sayles M, Kamel HA, Fahmy FF. Operative management of external auditory canal cholesteatoma: case series and literature review. J Laryngol Otol. 2013;127:859-66.

9. Bhagat S, Varshney S, Bist SS, Mishra S, Kabdwal N, Kumar R. Primary external auditory canal cholesteatoma presenting as cerebellar abscess. Indian J Otol. 2013;19:88-91.

10. Mahdoufi R, Tazi N, Barhmi I, Abada R, Mahtar M. Bilateral primitive cholesteatoma of external auditory canal with congenital stenosis. Int $\mathbf{J}$ Surg Case Rep. 2016;24:108-11.

Cite this article as: Hajare PS, Padmavathy O. Case series on external auditory canal cholesteatoma: an entity often misdiagnosed. Int J Otorhinolaryngol Head Neck Surg 2020;6:1179-82. 